\title{
Investigating EFL Teachers' Emotional Regulation Strategies in Second Language Learning Contexts
}

\author{
Kristian Florensio Wijaya \\ kristianwijaya500@gmail.com \\ Sanata Dharma University, Yogyakarta
}

\begin{abstract}
It is of clear importance for EFL teachers to better regulate their emotions while facing multivariate classroom vicinities offering undeniable uniqueness possessed by each learner. As a contradictory, EFL teachers frequently undergo emotional impairs during engaging in their vocation as burnout, emotional exhaustion, boredom, frustration, and reluctance. Responding to this serious teaching issue, emotional regulation strategies should be introduced earlier for EFL teachers in order to bring about positive teaching-learning influences for the whole school communities in terms of enjoyable learning activities, spirited learners, committed educators, and a solid rapport established among educational boards. This current study attempted to probe more profoundly on tangible emotional regulation strategies implemented by EFL teachers teaching in distinctive school institutions. The aim of this study was; what are the specific strategies EFL Teachers apply to regulate their emotions in second language learning contexts? This qualitative study utilized narrative inquiry to better obtain more obvious portrayals out of the teachers' real-time experiences of managing their emotional states for particular teaching periods. The findings of this study displayed that the diminution of EFL teachers' negative emotions will enable learners to achieve their gratifying learning outcomes and retain teachers to survive longer in their current vocation.
\end{abstract}

Keywords: emotional regulation strategies, EFL teachers, second language learning contexts, narrative inquiry

\section{INTRODUCTION}

In this era of disruption, language teachers' roles are considered as a pivotal bridge functioning to lead learners for the betterment of their future lives. Tangibly, language teachers are deemed as qualified when they are capable of managing the classroom, impart clearer learning instructions for learners, and monitor learners' learning progresses constantly. Stronge et al. (2007) state that to be more high-quality EFL teachers, they should be able to yield proper learning situations in which all learners can learn better. In partnership with this prior conception, good language teachers need also to induce a more conducive learning atmosphere, maintain a positive rapport with learners, and utilize various challenging learning tasks for their learners. Elawar and Lizzaraga (2010) repudiate that positive learning circumstances, the soundness of teacher-student relationships, and appropriate language learning tasks should be exerted at the commencement of L2 learning activities to enable all learners to achieve similar target language learning competencies. In keeping with all of these demanding faucets that should be shouldered by language teachers, it is fairly adduced here that teachers' emotional states need to be preserved in a positive way since the outcome of this result will heavily bring about significant effects for the whole target language learning processes and learners' futures. Vesely, et al (2013) promulgate that current teachers' emotional conditions will potentially influence the ongoing learning 
experiences undergone by learners. On the other extreme, since teaching is handicapped as a laborious, energy-draining, and pain-staking working arena, particularly dealing with unsupportive colleagues, unruly students, indifferent parents, stricter educational institutional rules, and lack of supports given by educational stakeholders, it is easier to discover that there is a great number of teachers who decided to quit from their current vocations as educators affected by those aforementioned issues. Newberry and Allsop (2017) discover that teaching is one of the challenging vocations offering a higher degree of mental and psychological pressure. This fact is calibrated with Hong's (2012) finding in his study of novice EFL teachers revealed that a great number of young teachers have dropped out from their current professions, which increase the teacher attrition rates annually. More specifically, there are other causalities affecting this teacher's attrition rate due to job dissatisfaction, emotional labor, unpleasant working circumstances, degraded self-motivation, and frequent emotional burnout incurred within teachers' minds (see Skaalvik and Skaalvik, 2016).

In line with preceding conceptions of teachers' responsibilities and psychological factors, it is indispensably for them to inculcate a higher level of positive emotions in the midst of adversity, impediments, and unpredictable working vicinities. This paramount action needs to be embodied fully at the outset of teaching-learning dynamics since it determines whether teachers can be stepping stones of stumbling blocks for their learners' learning success. Frenzel et al. (2014) succinctly reason that positive emotion infused within teachers' minds will promote a more enjoyable, positive, and conducive teaching-learning atmosphere for learners. On the one hand, teachers' negative emotions will also hamper the targeted learning activities directly cause a severe teaching-learning breakdown. In accord with these contentions, teachers' positive emotions can also potentially lead educators to internalize more creative, enlightening, and exhilarated teachinglearning dynamics in learners' presence. Garner (2010) propounds that positive emotions infused by teachers will encourage them to incorporate more lively teaching-learning dynamics where all learners are desirous of learning a wide array of information, keen on participating in every targeted learning activity, and committed to accomplishing any kinds of given tasks punctually. In a similar fashion, the emergence of teachers' positive emotions will also bring about successful promotions of robust learners' learning endeavors, positive relationships occurred among teacherstudent along with student-student interactions, and gratifying academic achievements.

In order to corroborate all of the previous conceptions about EFL teachers' emotions, the researcher will provide a concise glimpse of 5 prior studies conducted in the ELT fields dealing with teachers' strategies to run the teaching-learning activities more efficiently in the light of positive emotions. The first study was conducted by Jabu et al (2017). They discovered that various constructive feedback imparted from the lecturers to University Students were beneficial to provide the betterment of future learning processes and avert students to repeat similar mistakes in doing their tasks. As we discerned in the first study, although it was not conducted in the light of language teachers' emotional regulation strategies, the researcher believed that meaningful feedback addressed by the lecturers can only be bred by profound caring, constant attentiveness, and positive emotions substantiated between teacher-student relationships. Moving forward to the second study, Syamsinar and Jabu (2016) also revealed that language teachers' professional development was influenced by their prior previous teaching training and background knowledge of pedagogical competencies resulted in either successful or unsuccessful embodiment of teachinglearning dynamics. Toraby and Modarresi (2018) in their study of EFL Teachers' Emotions and 
Learners' Views of Teachers' Pedagogical Success displayed that more positive teaching-learning dynamics can be experienced fully by language learners when their teachers have ingrained such a positive emotion toward teaching vocation. Dewaele et al (2018) noted that teachers could preserve their positive emotions and give their best efforts in educating their students when they were exposed to supportive working conditions, learners' satisfaction with regard to materials delivery, and mutual workforce instances given continuously by other school stakeholders. In the last study focusing on EFL Teachers' Emotional Intelligence, Emotional Support, and Classroom Leadership, Khani (2019) exhibited that language teachers' positive emotions could possibly be nurtured by exposing more in-depth training for them on classroom leaderships in order to better equip them to readily confront any possible classroom challenges they might face in the future, meaningfully provide clearer delineations of specific lessons for their learners, and implement more suitable teaching-learning instructions along with dynamics in diverse classroom settings. These prior studies of EFL teachers' positive emotions and teaching-learning practices in a multitude of EFL classroom contexts had already broken new fertile ground for further investigations of specific strategies language teachers apply to preserve their positive emotions in the presence of learners. However, to the best of the researcher's knowledge, these five prior studies had not specifically delved into particular emotional strategies EFL teachers implement while facing serious pressure, obstructions, and challenges they face in their teaching vocations. Motivated by this assumption, the researcher was prompted to conduct a small-scale study investigating EFL Teachers' Emotional Regulation Strategies in Second Language Learning Contexts. In relation to this research background, one specific research inquiry was formulated in this study namely: What are the specific strategies EFL Teachers apply to regulate their emotions in second language learning contexts?

The following heeds its further attention on two relevant theories pertaining to EFL Teachers' emotional regulation strategies in EFL Teaching-Learning Contexts. These theories will provide a brief and an exhaustive overview regarding specific factors bolstering EFL teachers' positive emotions, unintended events causing the emergence of EFL teachers' Negative emotions, and more detailed explications along with exemplifications with regard to the development of EFL teachers' professional development in the light of their emotional state dynamics. Those two relevant theories are about emotions and emotional regulation.

\section{Emotions}

Since the early 1970s, there has been an increasing rate of the study conducted on humanbeings' emotions in teaching (see Sutton and Wheatley, 2003). In spite of the great body of research probing about human-beings' emotions, few researchers have not yet conducted more profound investigations of factors affecting teachers' emotions in teaching, sociocultural backgrounds promoting particular inducement of teachers' emotions, the mutual interplays between teachers' emotions and motivation to teach, and specific strategies teachers can possibly incorporate to regulate their emotions (see Sutton and Wheatley, 2003). Furthermore, according to Zembylas (2003), there were three major reasons why there had been a paucity of further investigations on teachers' emotions in the teaching fields. Firstly, most researchers had held a strong belief that teaching was heavily associated with cognitive activities, pedagogical competencies, and teaching-learning activities incorporated by teachers rather than affective states alike emotions. Secondly, the majority of researchers also deemed emotions as abstruse psychological constructs to be measured and there was no single valid research instrument suitable 
to gauge this uniquely human phenomenon. Lastly, emotions were also attributed as a trivial matter to be investigated further. Apart from these controversial remarks, emotions can be subdivided into two major criteria namely positive and negative emotions. As mentioned in the previous section, the inducement of continuous positive emotions will enable teachers to conduct more meaningful, enjoyable, and holistic teaching-learning processes for their learners since their mind will be fully occupied with brilliant, fresh, and creative ideas with regard to teaching. Sutton and Wheatley (2003) believe that teachers possessing positive emotions will engage learners to learn in a better purpose in the virtue of challenging, meaning-making, and fascinating learning fashions.

\section{Emotional Regulation}

This theory concerns people's capabilities in handling undesirable and current emotions rendered by internal or external factors. Put more simply, people possessing a higher ability to regulate their emotions in such a better purpose will generate more fruitful outcomes experienced by others as a tangible result of their stable emotional controls. Mayer and Salovey (1997) promulgate that individuals who exhort better emotional controls will produce more acceptable results of their responses toward other people's actions. In accord with this theory, decent emotional regulation should be possessed by language teachers in order to set up more positive emotional responses, readily confront a wide array of stressful working situations, and reinforce already established solid relationships with learners. This conception is closely interlinked with the theory of teachers' emotional regulation proposed by Myruski et al., (2018) stating that emotional regulation is of key importance for teachers to possess in order to annihilate the upcoming negative emotions potentially dwelling in their mind. Three relevant studies had attempted to further examine the paramount role of emotional regulation within ELT fields. In the first study, Ghanizadeh and Royaei (2015) in their study of the relationships among emotional regulation, emotional labor, and burnout conducted in EFL Iranian private language learning institutions displayed that both emotional regulation and labor promoted significant impacts for teachers' burnout. Biron and Veldhoven (2012) also suggested the need for educational institutions to reduce their teachers' administrative works in order to prevent the growth of negative emotions regarding their suppressing working circumstances. Eventually, Merida-Lopez and Extremera (2017) also certified that EFL teachers' emotional regulation in Spain was tightly interwoven with the adversity, laborious working conditions, and negative psychological conditions they experienced. Due to these ominous working circumstances, they advocated educational institutions to provide more intensive mental and psychological training to sustain teachers' positive emotions in a long-term manner.

\section{METHOD}

This is a qualitative study that attempted to investigate EFL teachers' emotional regulation strategies in second language learning contexts. Deveci and Onder (2013) argue that the major aim of a qualitative study is to attain clearer delineations with regard to specific phenomenons. The data was gathered on 23 December 2020 since two invited participants were willing to dedicate their time to give specific information regarding particular emotional regulation strategies they applied when teaching diverse EFL learners in different school institutions. Narrative inquiry in the form of an open-ended interview was also incorporated in this study to maintain the robustness of data gathering processes. Ary et al., (2018) believe that by doing openended interviews, the researchers will potentially obtain more authentic and valid data as they intended. To accomplish this study, two EFL teachers working in distinctive school institutions 
were invited. The first teacher has ever experienced teaching senior high school students possessing different learning preferences, proficiency, and styles in Public Vocational High School 2, Yogyakarta as one of the compulsory teaching courses to graduate from the English Education Study Program called real-time practice teaching. The second participant in this study has also experienced rich teaching experiences dealing with challenging working circumstances in De Brito Senior High School, Yogyakarta for 25 years. The major reason for inviting these two EFL teachers in this small-scale study was to possess such a clear depiction regarding conditions, situations, and experiences undergone by these two educators while confronting with hurdles along with unsavory events in their working circumstances in the light of specific emotional regulation strategies they implemented to handle these issues successfully. Thus, the obtained findings taken from these two participants, although not significant, will provide a fertile ground for future researchers and second language practitioners to better inform EFL teachers to implement some coping strategies to quench their negative emotions in the light of these two invited EFL teachers' perspectives.

\section{RESULTS AND DISCUSSIONS}

This chapter focused on displaying and delineating some specific stories told by two interviewees regarding their specific strategies in managing their emotions through second language classroom contexts. The first story recited about teacher's robust volitions to detach from various negative emotions hampering EFL learning dynamics, teacher-student relationships, and learners' impressions of their teachers. The second finding accentuated more exhaustively. As mentioned before, all of the portrayals of each theme will be depicted in a narrative way accompanied by some theories and prior research findings to present such clear-cut stories of emotional regulation strategies employed by EFL teachers in today's learning contexts.

\section{First Teacher's Voices: The Successful Management of Negative Emotions Will Yield a Receptacle of EFL Classrooms containing happiness}

As stated previously, EFL teachers have to be capable of managing their negative emotions well to promote more positive classroom climates, maintain positive rapports with learners, better manage the classroom learning dynamics, and impart the intended specific subject matters in such a better purpose. Similarly, the first teacher also repudiated the importance of detaching ourselves from negative emotions even these kinds of destructive feelings are still potently entrenched in our hearts and mind. Further, in her views as a young EFL teacher, the continual incurrence of teachers' positive emotions will not merely affect the whole classroom climates and learning processes but also learners' reverence towards their teachers. This kind of mutual interplays between teachers and learners should be considered as an essential trajectory since a higher degree of learning enjoyment, engagement, and persistence will persist longer among pupils. This essentialism of EFL teacher's positive emotions is in agreement with the theories of teachers' emotional regulation strategies proposed by Spilt, et al (2011) together with Newberry (2010). These experts had held a strong belief that either EFL teachers' positive or negative images are strongly affected by the way they behave in the presence of their learners, and most importantly, teachers possessing more positive nuance on teaching labors must be promoted more meaningful teaching-learning dynamics in which learners can establish more intimate relationships with their teachers as well. In conformance with all of these conceptions, further interview excerpts obtained from the first teacher are also showcased to provide ampler evidence in accord with this first research theme. 
[Interviewee 1: Yes, second language class is different from other classes. Teachers should be able to maintain their positive emotions so that they could provide supportive learning environment.]

[Interviewee 1: When I have a close relationship with the students. Yes, I think teaching and learning is a mutual relationship between students and teachers. Teachers should be students' friends so that students do not feel tense in classroom learning activity, particularly in EFL classroom where English (or target language) becomes the main factor which could promote students' anxiety.]

[Interviewee 1: Well, I guess students are not afraid of asking what they do not know or simply just having chit chat with me when I manage my negative emotions well.]

In line with the interplays between ongoing EFL classroom climates and teachers' existing emotions, it is also notable to be underscored here that emersion of teachers' positive emotions will also bring about gigantic impacts for learners' learning development and achievements. Put simply, teachers who potently committed to giving all the best they had for transforming their learners into more proficient academicians having possession of laudable characters, will far better in understanding learners' specific learning needs, problems, diversity, styles, and preferences. All of these ideal EFL teachers' characteristics are worthwhile to be incorporated in multivariate second language classroom contexts, particularly dealing with demotivated learners since a higher degree of positive emotions will enable these learners to feel accepted in their particular learning circumstances, which in turn, lead them to frame more sturdy learning motivation, resilience, and engagement in the presence of challenging learning tasks. In stark contrast, EFL teachers who adhere to their negative emotions in a long-term period will not be able to boost their learners' learning eagerness more efficiently since they continually establish such a negative lens toward teaching. This kind of attitude will demotivate learners to continue learning the targeted subject fields and gradually get them to pull themselves out from the ongoing teaching-learning dynamics. In their study of EFL students' perceptions of second language teachers' positive emotions influencing target language learning processes, Torabi and Noori (2019) revealed three specific characteristics of ideal EFL teachers severely aimed by second language learners. Firstly, qualified language teachers possessing positive emotions on their vocations are those who extensively address their profound caring for their learners in terms of learning needs, preferences, activities, and emotional labors faced by struggling learners. Secondly, they also found that the majority of EFL learners will improve their target language competencies along with characters in a better manner when they are fulfilled with sincere appraisals and intimate relationships with their teachers. Thirdly, enthusiastic, generous, and viable EFL teachers are highly appreciated by the majority of second language learners rather than emotional, tedious, and reluctant teachers. In a similar tone, the first teacher also confessed regarding the significance of EFL teachers to invest a higher level of positive emotions in multitude of target language learning vicinities. Those relevant excerpts can be discerned as follow.

[ Interviewee 1: Well, when it deals with teaching a classroom, students have diverse characteristics indeed. The main obstacle that I encounter is passive students who are reluctant to engage in the learning process. Of course sometimes I feel a little bit mad but I try to hide my feeling. Sometimes, when I have prepared the media but the students do not want to engage I also feel sad. But I feel happy when the students are active in the learning activity.] 
[ Interviewee 1: Well, actually I do not really pay attention on my feeling after being able to regulate my negative emotions. However, I just want to emphasize that regulating negative emotion often takes time. But, when we are strongly committing to handle our negative emotions, I am sure we will be able to infuse more positive atmosphere to our classes.]

Unexpectedly, the trajectory for EFL teachers to implant more positive emotions in their current teaching-learning surroundings encountered severe varied severe issues such as misbehaving students, unruly students, unsupportive school working fields, lack of supports from significant others; parents and school stakeholders, demanding working periods, and difficult life conditions outside school institutions. Believe it or not, all of these energy-draining and unsavory teachers' existing conditions will lead them to burnout, negative emotions, and a stronger tendency to drop out from their current vocations. All these aforementioned issues are positively interlinked with the theory of teacher burnout promulgated by Hascher and Hagenauer (2016) which opined that teachers' expectations of their particular school institutions, learners' mutual trust entrenched on their teachers' knowledge of subject-specific matters, and relationships established among parents, school stakeholders, and learners will fervently impact teachers' particular emotions on ongoing vocations. Nguyen (2014) states that teachers will easily undergo more negative emotional shapes when they are constantly exposed to unsupportive colleagues, school superiors, parents, and students. Furthermore, Cowie (2011) asserts that uncontrolled classroom circumstances consisting of misbehaving, passive, inattentive, restless, and demotivated students will also contribute to teachers' attrition rates annually. Said (2014) also argues that an excessive number of administrative school works will lead teachers to experience unpleasant and stressful situations leading them to experience a significant regress in their professionalism as educators. Due to the aforementioned hurdles hindering EFL teachers' professional development, dedication, and positive views toward teaching vocation, it is well-advised for all educational practitioners, particularly in Indonesia, to prepare all teachers to regulate their emotions in the midst of challenging and demanding teaching vocation dynamics by conducting more intensive affective training heeding more profound attention on emotional regulation strategies, leadership skills, classroom management, and emotional supports. By doing so, all EFL teachers will be able to shift the negative lens of their teaching vocation to become more positive, run more meaning-making teaching-learning dynamics for their learners, and manage their classroom vicinities for a better purpose. All of these suggestions are tightly interlaced with the findings discovered by Khani (2019) in his study of EFL teachers' emotional intelligence, emotional support, and classroom leadership which advocated that educational institutions need to provide considerable affective teaching training for teachers focusing on emotions and leaderships to enable them to design more suitable instructional learning materials, incorporate more meaningful classroom activities, foster both learners' target language competencies and characters, and assist learners to undergird such a positive emotion throughout ongoing teaching-learning dynamics. More and less, other prior studies approved the urgent need to conduct more intensive affective teaching vocation training believe to equip EFL teachers' morality and well-being as well. In their study of University EFL teachers' well-being and emotional regulation, Talbot and Mercer (2018) revealed that EFL teachers have to be well-trained to identify particular situations driving them to infuse negative emotions resulted in various unintended teaching-learning events such as burnout, anger, displeasure, disinterest, and disappointment to provide more supportive assistances for them to reduce their negative emotions more efficiently. Fathi and Derakhasan (2019) conducted an indepth investigation on EFL teachers' self-efficacy and emotional regulation as predictors of 
teaching stress also propounded that educational institutions had to liberate their teachers to implement varied appropriate teaching-learning dynamics, the unique design of their instructional materials, and explore any other reliable learning materials potentially promote significant enhancement regarding learners' proficiency to activate their agency, professional development, and positive emotions concurrently. Relatedly, the first teacher also bolstered all of the abovementioned conceptions concerning EFL teachers' emotional training in second language classroom contexts. The excerpts can be seen as follow.

[Interviewee 1: I believe that by having emotion-regulation ability, I could stay on the teaching vocation. But I think every job always needs emotion-regulation ability. However, teachers always encounter problems in daily teaching and learning basis which could drain teachers' energy. The problems do not always occur in the classroom but it can happen among teachers, colleagues, parents, or even school staff or administrator.]

[Interviewee 1: Yes, it has already explained before. Well, the easiest thing that I do in the classroom is just taking a deep breath. I think I do not have specific strategy to regulate my emotions.]

\section{Second Teacher's Voices: EFL Teachers Will Fully Survive Through the Hailstorm Discovered in Their Vocation by Mitigating the Emergence of Negative Emotions}

It is worth highlighting here that EFL teachers' capabilities of managing the inducement of their negative emotions derived from both internal and external factors as a crucial matter. In line with learners' learning and emotional needs, it is indispensable for EFL teachers to carry out this challenging action to promote more conducive learning circumstances where all learners' emotions are apprehended by their teachers resulted in a pleasurable learning atmosphere together with fruitful learning outcomes. This contention is congruent with the theory of emotional regulation postulated by Sharma (2016). She contended that sensible EFL teachers possessing more stable emotions will potentially able to show more exhaustive intensive caring toward their learners and more flexibly make themselves more adaptive to various challenging learning situations. In a similar tone, Saric and Steh (2017) consent that teachers who are more cognizant of their negative and positive emotions will be better controllers over their unpredictable classroom vicinities. More specifically, the second EFL teacher also shared similar perspectives as follows.

[Interviewee 2: It is of importance for managing both internal and external emotion in tackling the barriers, challenges, and laborious situations. For that reason, it is the key success to guide and direct us to do and think what is right for a particular situation that can obviously have massive consequences upon the way we think, feel and behave to achieve our goal. Shortly, our emotions enable us to act, since as human beings, we can not only act logically (rationally) but also emotionally.]

[Interviewee 2: It is essential for EFL teachers to apply emotional regulation strategies for teaching English as a foreign language because teaching EFL involves a great deal of emotional labor. To regulate emotions is important to generate a positive response in others. When planning, organizing, and managing a class, an EFL teachers needs to engage with his/her students and care about them. Caring involves emotional labor.] 
As a clearer discernment, EFL teachers frequently encounter burnout, emotional exhaustion, frustration, and boredom in their teaching vocation due to the incongruence between their prior expectations and current classroom conditions, ample hindrances hindering the smooth applications of determining teaching-learning objectives, and unfavorable working conditions. All of these unsavory teachers' conditions are in agreement with emotional labor events proposed by Golombek and Doran (2014). They believed that the discrepancy of predictions and actual expectations regarding future teaching environments inculcated in teachers' minds will probably create some emotional contradictions enabling teachers to leave their professions earlier. Chang (2009) also argues that when the teachers' teaching-learning objectives have already met the school demands, they are more likely to possess more positive emotions toward their current vocation. Contrarily, while teachers' teaching-learning goals are heavily destructed by misbehaving, passive, unruly, and rebellious students, the negative emotions of their profession will increase dramatically. Further, Keller et al. (2014) contend that the impetus of teachers' negative emotions may also emerge from external causes such as lack of parents' supports, uncooperative working counterparts, heavy administrative workloads, inadequate salary, and lack of institutional supports. Definitely, all of these three common factors need not be disregarded by teachers, school institutions, parents, and learners for more frustrated and uncommitted educators will be bred from this vicious trajectory. Hence, to better arm EFL teachers with more adequate supplies virtuous for their emotional states, they should be able to conduct more profound selfreflection with regard to specific events rendering both positive and negative emotions. After having recognized all of these cruxes of the matters, teachers can train themselves to put greater restraints over their current emotional appearance in order to ascertain that every unintended emotional disturbance will not make learners receive a gigantic brunt on their learning events. These above-mentioned strategies are resonated well with the theory of emotional regulation propounded by Chen (2016). He denoted that teachers need to identify some tangible causes prompting negative emotions in order to enable them to become more judicious educators cultivating more positive emotions and address better learning assistance for their learners in terms of cognitive and emotional development. Heydarnejad, Watt, and Devos (2017) also reveal that teachers have to possess a decent capability to regulate their emotional states, particularly in school contexts, in order to promote more positive nuances on the ongoing teaching-learning dynamics. In like manner, Akbari, et al (2017) showcase that current teachers' emotional deployment is tightly interwoven with their pedagogical practices, which in turn, will directly affect learners' learning needs, working place, and the perceptions of teaching vocation itself. Following all of these paramount needs for teachers, it is also interesting enough to correlate the current conceptions of emotional management strategies with the second teacher's views as follows.

[Interviewee 2: When encountering the negative emotions, I am accustomed to talking and discussing with the students both classically and individually about what makes such emotions emerge. The discussion and the talk focus on the factors that stimulate the negative emotions.]

[Interviewee 2: As a teacher, I undergo a number of emotional experiences which back me up to stay on the track of teaching as my vocation where I possess various types of relationship with colleagues, students, parents, and administrators. I feel contented with my practices when the course objectives meet the mission of the school, which is to shape the students who are competent, full of caring, passionate, consistent, and committed as leaders of service.] 
[Interviewee 2: At last, what makes me stay longer to be loyal to my vocation is not only on awareness to emotion regulation, but also on values clarification regarding the emotional experiences with the whole school community.]

\section{CONCLUSIONS, IMPLICATIONS, AND SUGGESTIONS}

All in all, there are three major big-takeaways taken for serious consideration to retaining EFL global teachers to survive in their challenging teaching vocation namely an intimate emotional rapport established with learners, successful identifications of particular events prompting the inducement of teachers' negative emotions, and a higher degree of self-commitment amid thorny working circumstances. Following this thread, a great number of participants and more significant variables boosting EFL teachers' negative emotional states should also put into such a wholehearted consideration for future researchers who are willing to run identical studies in this realm in order to produce more significant research results beneficial for EFL educational experts, practitioners, and educators all around the globe.

\section{REFERENCES}

Akbari, R., Samar, R. G., Kiany, G. R., \& Tahernia, M. (2017). A qualitative study of EFL teachers' emotion regulation behavior in the classroom. Theory and practice in Language Studies, 7(4), 311-321.

Ary, D., Jacobs, L. C., Irvine, C. K. S., \& Walker, D. (2018). Introduction to research in education. Cengage Learning.

Biron, M., \& Van Veldhoven, M. (2012). Emotional labour in service work: Psychological flexibility and emotion regulation. Human Relations, 65(10), 1259-1282.

Cardelle-Elawar, M., \& de Acedo Lizarraga, M. L. S. (2010). Looking at teacher identity through self-regulation. Psicothema, 22(2), 293-298.

Chang, M. L. (2009). An appraisal perspective of teacher burnout: Examining the emotional work of teachers. Educational psychology review, 21(3), 193-218.

Chen, J. (2016). Understanding teacher emotions: The development of a teacher emotion inventory. Teaching and Teacher Education, 55, 68-77.

Cowie, N. (2011). Emotions that experienced English as a foreign language (EFL) teachers feel about their students, their colleagues and their work. Teaching and Teacher Education, 27(1), 235-242.

Deveci, İ., Önder, İ., \& Çepni, S. (2013). Parents'Views Regarding Homeworks Given in Science Courses. Journal of Baltic Science Education, 12(4).

Dewaele, J. M., Witney, J., Saito, K., \& Dewaele, L. (2018). Foreign language enjoyment and anxiety: The effect of teacher and learner variables. Language teaching research, 22(6), 676697. 
Fathi, J., \& Derakhshan, A. (2019). Teacher self-efficacy and emotional regulation as predictors of teaching stress: An investigation of Iranian English language teachers. Teaching English Language, 13(2), 117-143.

Garner, P. W. (2010). Emotional competence and its influences on teaching and learning. Educational Psychology Review, 22(3), 297-321.

Ghanizadeh, A., \& Royaei, N. (2015). Emotional facet of language teaching: Emotion regulation and emotional labor strategies as predictors of teacher burnout. International Journal of Pedagogies and Learning, 10(2), 139-150.

Golombek, P., \& Doran, M. (2014). Unifying cognition, emotion, and activity in language teacher professional development. Teaching and Teacher Education, 39, 102-111.

Hascher, T., \& Hagenauer, G. (2016). Openness to theory and its importance for pre-service teachers' self-efficacy, emotions, and classroom behaviour in the teaching practicum. International Journal of Educational Research, 77, 15-25.

Heydarnejad, T., Hosseini Fatemi, A., \& Ghonsooly, B. (2017). An Exploration of EFL Teachers' Teaching Styles and Emotions. Journal of Applied Linguistics and Language Research, 4(2), 26-46.

Hong, J. Y. (2012). Why do some beginning teachers leave the school, and others stay? Understanding teacher resilience through psychological lenses. Teachers and Teaching, 18(4), 417-440.

Jabu, B., Noni, N., Talib, A., \& Syam, A. (2017). Lecturers' use of corrective feedback and students' uptake in an Indonesian EFL context. Global Journal of Engineering Education, 19(1), 82-87.

Keller, M. M., Chang, M. L., Becker, E. S., Goetz, T., \& Frenzel, A. C. (2014). Teachers' emotional experiences and exhaustion as predictors of emotional labor in the classroom: An experience sampling study. Frontiers in psychology, 5, 1442.

Khany, R. (2019). EFL Teachers' Emotional Intelligence, Emotional Support, and Their Classroom Leadership: A Structural Equation Modeling Approach. International Journal of Research in English Education, 4(3), 1-20.

Mayer, J. D., \& Salovey, P. (1997). What is emotional intelligence. Emotional development and emotional intelligence: Educational implications, 3, 31.

Mérida-López, S., \& Extremera, N. (2017). Emotional intelligence and teacher burnout: A systematic review. International Journal of Educational Research, 85, 121-130.

Myruski, S., Gulyayeva, O., Birk, S., Pérez-Edgar, K., Buss, K. A., \& Dennis-Tiwary, T. A. (2018). Digital disruption? Maternal mobile device use is related to infant social-emotional functioning. Developmental science, 21(4), e12610. 
Newberry, M. (2010). Identified phases in the building and maintaining of positive teacher-student relationships. Teaching and Teacher Education, 26(8), 1695-1703.

Newberry, M., \& Allsop, Y. (2017). Teacher attrition in the USA: The relational elements in a Utah case study. Teachers and Teaching, 23(8), 863-880.

Nguyen, M. H. (2014). Preservice EAL Teaching as Emotional Experiences: Practicum Experience in an Australian Secondary School. Australian Journal of Teacher Education, 39(8), n8.

Said, S. B. (2014). 11 Teacher identity development in the midst of conflicting ideologies. Advances and current trends in language teacher identity research, 148.

Saric, M., \& Steh, B. (2017). Critical reflection in the professional development of teachers: Challenges and possibilities. CEPS journal, 7(3), 67-85.

Sharma, S. (2016). To find the relationship of professional commitment of teacher educator with emotional intelligence socio-economic status. ACADEMICIA: An International Multidisciplinary Research Journal, 6(12), 136-143.

Skaalvik, E. M., \& Skaalvik, S. (2016). Teacher stress and teacher self-efficacy as predictors of engagement, emotional exhaustion, and motivation to leave the teaching profession. Creative Education, 7(13), 1785.

Spilt, J. L., Koomen, H. M., \& Thijs, J. T. (2011). Teacher wellbeing: The importance of teacherstudent relationships. Educational psychology review, 23(4), 457-477.

Stronge, J. H., Ward, T. J., Tucker, P. D., \& Hindman, J. L. (2007). What is the relationship between teacher quality and student achievement? An exploratory study. Journal of personnel evaluation in education, 20(3-4), 165-184.

Sutton, R. E., \& Wheatley, K. F. (2003). Teachers' emotions and teaching: A review of the literature and directions for future research. Educational psychology review, 15(4), 327-358.

Syamsinar, S., \& Jabu, B. (2016). The problems in professional competence of teachers in teaching English subject at Vocational High Schools. ELT WORLDWIDE, 2(2), 95-109.

Talbot, K., \& Mercer, S. (2018). Exploring university ESL/EFL teachers' emotional well-being and emotional regulation in the United States, Japan and Austria. Chinese Journal of Applied Linguistics, 41(4), 410-432.

Torabi, M., \& Noori, S. M. (2019). Religious leaders and the environmental crisis: Using knowledge and social influence to counteract climate change. The Ecumenical Review, 71(3), 344-355.

Toraby, E., \& Modarresi, G. (2018). EFL Teachers' Emotions and Learners' Views of Teachers' Pedagogical Success. International Journal of Instruction, 11(2), 513-526. 
Vesely, A. K., Saklofske, D. H., \& Leschied, A. D. (2013). Teachers-The vital resource: The contribution of emotional intelligence to teacher efficacy and well-being. Canadian Journal of School Psychology, 28(1), 71-89.

Zembylas, M. (2003). Emotions and teacher identity: A poststructural perspective. Teachers and Teaching, 9(3), 213-238. 